\title{
Endoscopic Surgery for Recurrent Disc Herniation After Microscopic or Endoscopic Lumbar Discectomy
}

\author{
Burcu GOKER ${ }^{1}$, Salih AYDIN² \\ ${ }^{1}$ Istinye University, School of Medicine, Liv Hospital Ulus, Department of Neurosurgery, Istanbul, Turkey \\ ${ }^{2}$ Emsey Hospital, Department of Neurosurgery, Istanbul, Turkey
}

Corresponding author: Burcu GOKER burcugoker79@yahoo.com

\section{ABSTRACT}

AIM: To determine the feasibility and efficacy of full endoscopic interlaminar discectomy (FEID) for recurrent disc herniation.

MATERIAL and METHODS: This retrospective single-center study included 60 patients. Among them, 36 who previously had microdiscectomy underwent revisional FEID (MD group), and 24 who previously had FEID underwent revisional FEID (FEID group). In addition to general parameters, the following measurement tools were used: visual analog scale (VAS) and Oswestry disability index (ODI) questionnaire.

RESULTS: No statistically significant difference was observed in length of hospitalization, time to return to work, complications, and recurrences between the two groups. Both the FEID and MD groups had a significant decrease in postoperative VAS and ODI scores. The mean operation time was shorter in the FEID group than in the MD group, and the result was significantly different $(p<$ 0.05). During the 36-month follow-up, no significant differences were observed in postoperative VAS and ODI scores between the two groups. Moreover, none of the patients developed complications correlated to surgery. However, three patients with a previous history of microdiscectomy or endoscopic discectomy had recurrence despite revisional endoscopic surgery.

CONCLUSION: Percutaneous revisional full endoscopic lumbar disc surgery is a safe and effective procedure that does not cause additional structural damage. Full endoscopic technique can be used safely for recurrent disc herniations regardless if a patient underwent microscopic or endoscopic surgery.

KEYWORDS: Endoscopic discectomy, Interlaminar discectomy, Recurrent lumbar disc herniation, Lumbar microdiscectomy, Minimally invasive spine surgery

ABBREVIATIONS: FEID: Full-endoscopic interlaminar discectomy, VAS: Visual analog scale, ODI: Oswestry disability index, MD: Microsurgical discectomy, RF: Radiofrequency

\section{INTRODUCTION}

$\mathrm{T}$

The rate of recurrence after microdiscectomy ranges from $5 \%$ to over $20 \%(4,5)$. The success rate of revisional lumbar disc herniation surgery may be lower than that of the initial operation, which is primarily attributed to postoperative epidural scarring, progradient degeneration with stenosis, arachnoiditis, segmental instability, or additional tissue damage $(6,15)$. Epidural scarring may lead to an increased risk of injury to the dura or adjacent neural structures (15). Minimally invasive techniques can reduce tissue damage and its correlated complications $(11,13)$. Nowadays, with the help of endoscopic technology, new endoscopic techniques are presented in the literature, which have similar clinical outcomes and less complication rates compared to conventional open and microscopic surgery $(11,13,26)$. 


\section{MATERIAL and METHODS}

After the study was approved by the institutional review board (Liv Hospital; Approval No: 15; 16.01.2019), 60 patients with clinically symptomatic recurrent disc herniation were retrospectively included. A total of 36 patients who previously had microdiscectomy as the initial surgery underwent revisional full endoscopic interlaminar discectomy (FEID; MD group), and 24 patients who previously had FEID as the initial surgery underwent revisional FEID (FEID group) between 2012 and 2015. The indication for surgery was defined according to present-day standards based on radicular pain symptoms, existing neurologic deficits, and current lumbar magnetic resonance imaging findings $(2,17)$. The pre- and postoperative visual analog scale (VAS)and Oswestry disability index (ODI) scores were used for pain assessment (12). Final followup examinations were conducted 36 months after surgery. All patients answered the appropriate questionnaire via telephone after 3, 6, and 12 months. The final examinations were performed at the clinic during the 36-month follow-up visit.

\section{Operative Technique}

All operations were performed under general anesthesia. The full endoscopic interlaminar operation was conducted with the standart technique previously described by Ruetten et al. $(16,20-22)$. A dilator was inserted bluntly to the lateral edge of the interlaminar window, and an operating sheath, which has an oblique opening at the distal end, was directed toward the lateral aspect of the radix. The procedure was performed under visual control, and constant irrigation was carried out (Figure 1). The medial edge of the facet joint was identified and exposed.

Blunt dissection was performed on the floor of the spinal canal, and the ventral epidural space was prepared. Expanding the bone resection of the interlaminar window is usually required to enhance the visualization of the spinal canal.

In revisional disc surgery, the widening of the current hemilaminectomy defect particularly at the L4-5 segment and above that level is not always required. However, if the interlaminar range is narrow, partial dissection of the scar tissue from the medial margin facet joint with an annulotome and dissector may be required. The scar tissue was separated from the medial facet joint with the tip of the beveled working channel using a gentle forward twisting motion under direct visualization, and the soft tissue was removed via radiofrequency (RF) coagulation. While removing the dense scar tissue, the safest method was to start as far as possible from the lateral side and then to reach the medial side until the medial facet joint was visible. This maneuver facilitated the visualization of the root and related neural structures. Under constant irrigation, a gentle forward twisting motion to the medial side with the working channel was extremely effective, and it helped differentiate the disc level from the herniated disc fragment. The use of this maneuver facilitated the removal of the herniated disc fragments.

\section{Statistical Analysis}

Statistical analyses were performed using the Statistical Package for the Social Sciences software for Windows version 21.0 (IBM SPSS Corp., Armonk, NY, the USA). Quantitative data were presented as mean \pm standard deviation. Chi-square test was utilized for categorical data between the two groups and for comparison between preoperative and postoperative results. The Mann-Whitney $U$ test and paired $t$-test were used to compare the preoperative and postoperative VAS scores and ODI parameters. A p value $<0.05$ was considered statistically significant.

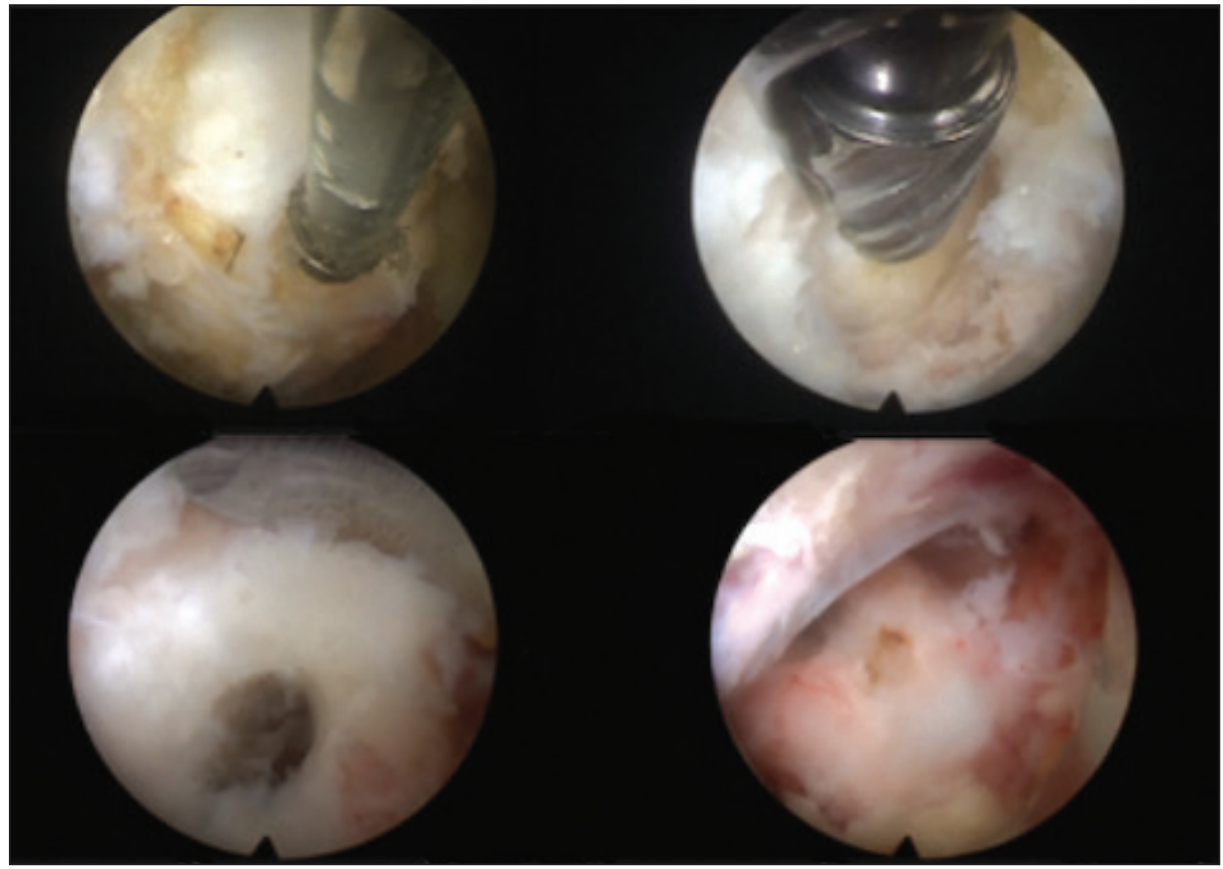

Figure 1: As shown in these intraoperative endoscopic images, the scar tissue was separated from the medial facet joint with the oblique tip of the working channel using a gentle forward twisting motion under direct visualization, and the soft tissue of the medial facet was cleaned and expanded via radiofrequency. 


\section{RESULTS}

\section{Baseline Characteristics of the Participants}

Among the participants, 16 were women and 44 men who were aged between 25 and 80 (mean=46) years. The onset of pain from the time of operation ranged from 5 days to 3 months (mean=39 days). Twenty patients received conservative treatment for 2 weeks on average from the onset of pain. The duration from the initial surgery to revisional surgery was 28 months on average (5 days to 41 months). Of 24 patients who had endoscopic surgery as the initial surgery, 19 underwent primary surgery at our clinic. The other five patients underwent operation else where and were referred to our clinic for revisional surgery. According to our experience, in 857 patients who had endoscopic discectomy as the primary surgery, the recurrence rate was $2 \%(n=19)$ during the study period. Since our clinic has focused on endoscopic discectomy procedures for several years, all patients who had microscopic discectomy as the initial surgery from other clinics were referred to our clinic for revision surgery. Thus, we have no data about primary recurrence rate. According to the literature, the recurrence rate after microscopic discectomy increased from $5 \%$ to $15 \%$ (27).

\section{Study Groups}

Among 36 patients with a history of microdiscectomy (MD) as the initial surgery, 11 had surgery at the L5-S1 level, 19 at the L4-5 level, and six at the L3-L4 level. Among 24 patients with a history of FEID as the initial surgery, 17 had surgery at the L5-S1 level and seven at the L4-L5 level. In the MD group, 30 of 36 patients had broad-based herniations. Mean while, in the FEID group, 19 of 24 patients had narrow-based disc herniations.

\section{Outcome}

As shown in Table I, patients from both the FEID and MD groups had similar clinical characteristics. No statistically significant differences were observed in terms of age, gender, duration of symptoms, and type of herniated discs between the two groups.

The general outcome parameters are summarized in Table II. The mean operation times were $29.2 \pm 9.0$ minutes in the FEID group and $36.8 \pm 11.4$ minutes in the MD group, and the results were significantly different $(p<0.05)$. The operation time was defined as the time from skin incision to the end of wound closure. No statistically significant difference was observed in the mean average length of hospital stay, average time to return to work, complications, and recurrences between the two groups ( $p>0.05)$.

The general preparation before and after the operation was similar in both groups. There was no measurable blood loss intraoperatively. Complete removal of the sequestered disc material was achieved in all patients. In 24 (66\%) patients in the MD group, osseous resection of the medial facet joint was required. However, osseous resection was not required in the FEID group (Figures 2 and 3).

The preoperative and postoperative VAS scores for leg/back pain and the ODI scores of both groups are summarized in Table III. In the FEID group, the VAS scores for leg and back pain decreased from $8.7 \pm 0.7$ and $4.8 \pm 2.2$ preoperatively to $0.2 \pm 0.1$ and $0.3 \pm 0.6$ postoperatively during the final followup, respectively $(\mathrm{p}<0.05)$. The preoperative ODI score was 45.6 \pm 19.3 , which decreased to $12.7 \pm 5.2$ during the final followup $(p<0.05)$. In the MD group, the preoperative VAS scores for leg and back pain decreased from $8.5 \pm 1.1$ and $5.1 \pm 1.6$ preoperatively to $0.3 \pm 0.1$ and $0.4 \pm 0.8$ postoperatively during

Table I: Demographic Data of all Patients

\begin{tabular}{lccc}
\hline Demographic data & FEID Group & MD Group & p \\
\hline Number of patients & $24(40.0 \%)$ & $36.0 \%)$ & $>0.05$ \\
\hline Mean age (years) & $46.6 \pm 10.9$ & $47.6 \pm 8.6$ & $>0.05$ \\
\hline Sex (male/female) & $16 / 8$ & $27 / 9$ & $>0.05$ \\
\hline Mean duration of symptoms (months) & $1.3 \pm 06$ & $1.3 \pm 0.7$ & $20 / 16$ \\
\hline Herniation type (extrusion/sequestered) & $13 / 11$ & $>0.05$ & \\
\hline
\end{tabular}

FEID: Full Endoscopic Interlaminar Discectomy, MD: Microsurgical Discectomy

Table II: General Parameters of the Full Endoscopic Interlaminar Discectomy (FEID) and Microsurgical Discectomy (MD) Groups

\begin{tabular}{lccc}
\hline General parameters & FEID Group & MD Group & p \\
\hline Mean operative time (minutes) & $29.2 \pm 9.0$ & $36.8 \pm 11.4$ & $<0.05$ \\
\hline Mean length of hospital stay (days) & $15.1 \pm 1.6$ & $15.7 \pm 1.4$ & $>0.05$ \\
\hline Mean time to return to work (day) & $13.1 \pm 2.8$ & $13.9 \pm 2.2$ & $>0.05$ \\
\hline Complications & $1(5.2 \%)$ & $2(5.6 \%)$ & $>0.05$ \\
\hline Recurrences & $1(5.2 \%)$ & $2(5.6 \%)$ & $>0.05$ \\
\hline
\end{tabular}



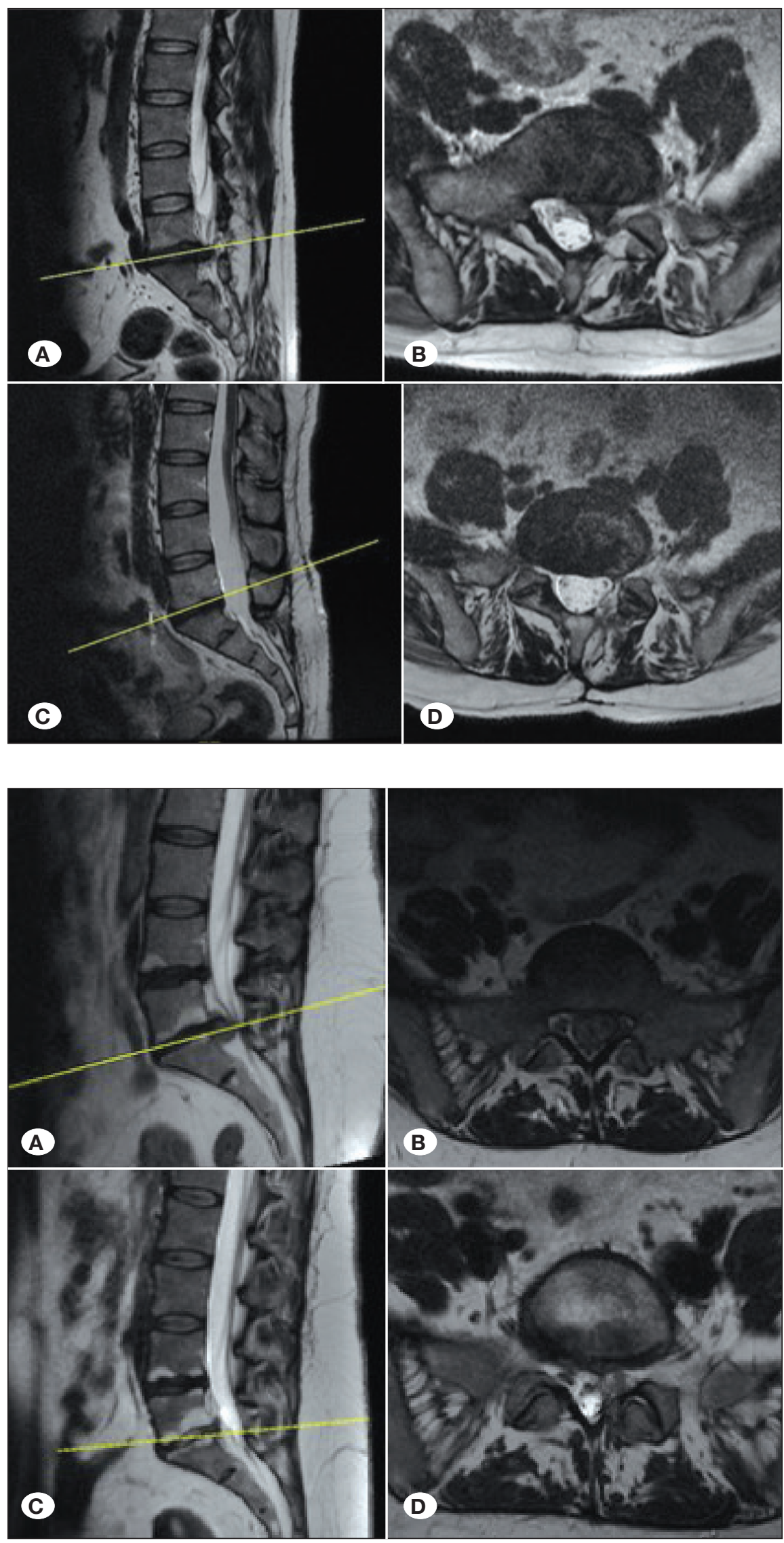

Figure 2: Preoperative (A, B) and postoperative (C, D), sagittal (A, C) and axial (B, D) T2 sequence magnetic resonance imaging findings of a patient who had endoscopic discectomy after a previous microdiscectomy on the left L5-S1 level.
Figure 3: Preoperative (A, B) and postoperative (C, D), sagittal (A, C) and axial (B, D) T2 sequence magnetic resonance imaging findings of a patient who had endoscopic discectomy operation after a previous endoscopic discectomy on the left L5-S1 level. 
the final follow-up, respectively $(\mathrm{p}<0.05)$. The preoperative ODI score was $46.8 \pm 17.9$ points, which decreased to $12.5 \pm 4.8$ during the final follow-up $(p<0.05)$. No significant difference was observed in the mean preoperative and postoperative VAS and ODI scores between the two groups (Table III, Figure 4).

No dural injury was observed in any of the cases. None of the patients presented with serious neurologic deficits or complications, such as nerve root injury or cauda equina syndrome. However, three patients who underwent revisional FEID after an initial microdiscectomy operation had postoperative paresthesia. However, they recovered after 3 weeks. In two (5.6\%) patients in the MD group, recurrences were observed within 2 months after the operation. In one
(5.2\%) patient in the FEID group, recurrence was observed 2 weeks after operation. These patients underwent revisional FEID again with the same technique.

\section{DISCUSSION}

The standart treatment for lumbar disc herniation is microscopic discectomy because of its favorable outcomes $(3,10)$. Ruetten et al. have reported that full endoscopic discectomy and microscopic open discectomy have similar outcomes $(16,19-21)$. Endoscopic discectomy has advantages, which include shorter recovery time, less opioid use due to less tissue damage, and less epidural scarring $(21,24)$. For revisional disc surgery, the standard surgical treatment has been microscopic discectomy with decompression. Recently,

Table III: Clinical Outcomes of the Full Endoscopic Interlaminar Discectomy (FEID) and Microsurgical Discectomy (MD) Groups

\begin{tabular}{lcccccc}
\hline Outcomes & \multicolumn{5}{c}{ Postoperative follow-up } \\
\hline & Group & Preoperative & $\begin{array}{c}\text { 3-month } \\
\text { follow-up }\end{array}$ & $\begin{array}{c}\text { 6-month } \\
\text { follow-up }\end{array}$ & $\begin{array}{c}\text { 1-year } \\
\text { follow-up }\end{array}$ & $\begin{array}{c}\text { Final } \\
\text { follow-up }\end{array}$ \\
\hline VAS leg pain score & FEID & $8.7 \pm 0.7$ & $0.04 \pm 0.2$ & $0.3 \pm 0.4$ & $0.4 \pm 0.49$ & $0.2 \pm 0.1$ \\
\cline { 2 - 7 } & MD & $8.5 \pm 1.1$ & $0.08 \pm 0.3$ & $0.4 \pm 0.5$ & $0.5 \pm 0.51$ & $0.3 \pm 0.1$ \\
\hline \multirow{2}{*}{ VAS back pain score } & FEID & $4.8 \pm 2.2$ & $1.5 \pm 2.1$ & $0.8 \pm 0.7$ & $0.5 \pm 0.6$ & $0.3 \pm 0.6$ \\
\cline { 2 - 7 } & MD & $5.1 \pm 1.6$ & $1.6 \pm 0.8$ & $0.8 \pm 0.8$ & $0.6 \pm 0.8$ & $0.4 \pm 0.8$ \\
\hline \multirow{2}{*}{ ODI scores (\%) } & FEID & $45.6 \pm 19.3$ & $20.5 \pm 5.1$ & $16.8 \pm 5.1$ & $13.8 \pm 5.2$ & $12.7 \pm 5.2$ \\
\hline & MD & $46.8 \pm 17.9$ & $20.8 \pm 4.1$ & $16.8 \pm 5.0$ & $13.6 \pm 5.1$ & $12.5 \pm 4.8$ \\
\hline
\end{tabular}

No Significant Difference was Observed in Terms of the Preoperative Visual Analog Scale (VAS) and Oswestry Disability Index (ODI) Scores between the Full Endoscopic Interlaminar Discectomy (FEID) and Microsurgical Discectomy (MD) groups ( $>>0.05)$. The Preoperative VAS and ODI Scores Significantly Improved in both Groups $(p<0.05)$. No Significant Differences were Observed in Terms of the Postoperative VAS and ODI Scores between the Two Groups ( $p>0.05)$.

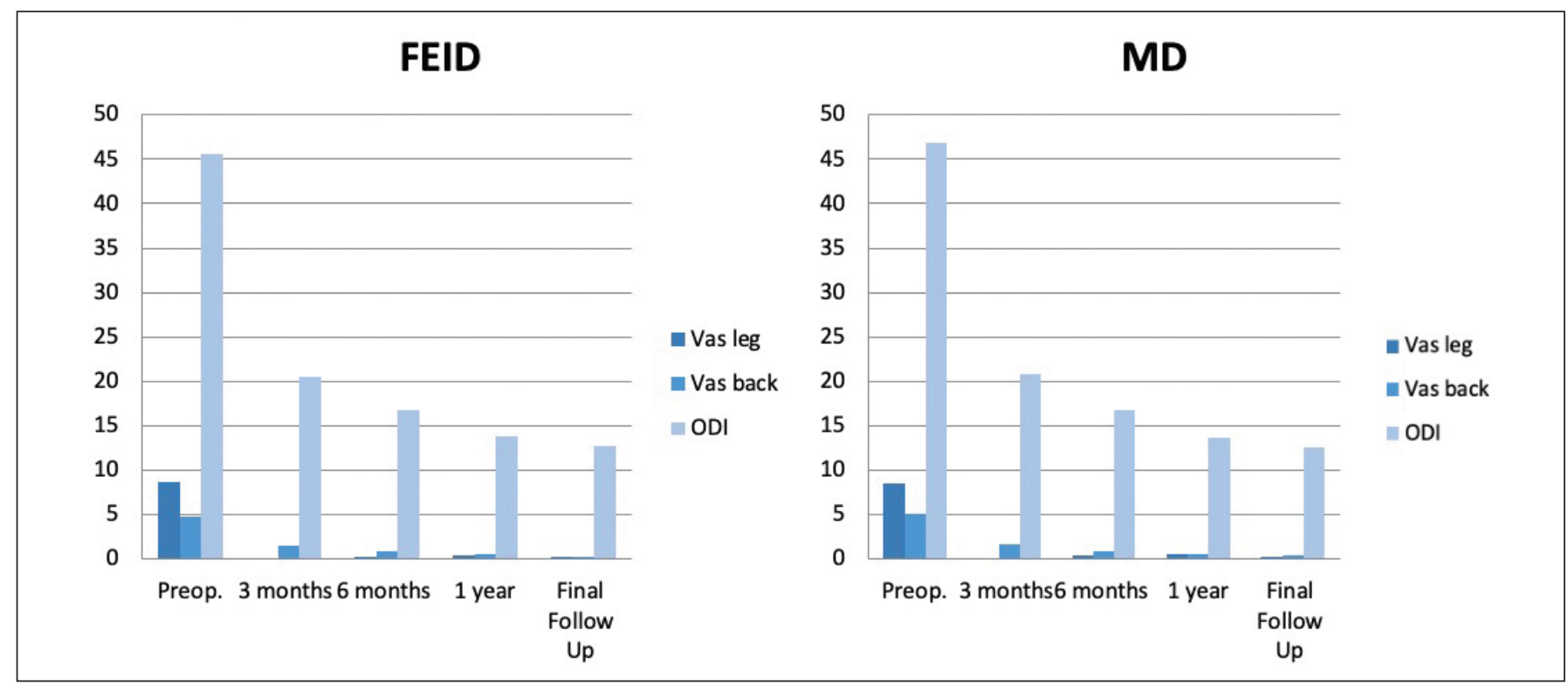

Figure 4: Mean visual analog scale scores for leg and back pain and Oswestry disability index scores of the Full Endoscopic Interlaminar Discectomy and Microsurgical Discectomy groups. 
endoscopic discectomy is gaining popularity over the standard microdiscectomy because of its advantages, such as less tissue trauma, cerebrospinal fluid leakage, and infection rate. In addition, in our study, the notion stating that the augmented rate of narrow-based recurrent disc herniations after endoscopic discectomy supports the minimal invasive nature of the procedure. Since the endoscopic technique is not a standard microsurgical technique, surgeons may not use such technique due its steep learning curve. However, several reports have shown that endoscopic discectomy had similar clinical outcomes to microdiscectomy, with less complication rates when performed by experienced surgeons $(21,25)$. Therefore, one must keep in mind that early learning stage of this surgery may lead to higher complication rates (28).

Revisional disc surgery has higher complication rates than primary disc surgery. Epidural scarring is a major problem of revisional discectomy leading to neural damage and dural tear (1). Ebeling et al. have reported a complication rate of $13 \%$ after repeated microscopic discectomy, and dural tears or infections are the most common problems (9). The use of the interlaminar endoscopic approach overcame this problem as it is a feasible solution. Using the endoscopic technique, dissection of the epidural scar tissue is performed cranially and medially with a sharp freer, endoscopic curette, and radiofrequency coagulation to identify ruptured disc fragments. If a dural tear is observed during endoscopic revisional surgery, sutures must not be used to repair the dura. Sencer et al. have emphasized that cerebrospinal fluid leakage could be prevented without a primary dural repair in case of dural injury, which is the result of a narrow working field during endoscopic discectomy surgery (24). We support such finding based on our experience and low rates of cerebrospinal fluid leakage.

In our series, none of the patients presented with dural tear because an experienced team at our clinic performed the procedure. Furthermore, the length of hospital stay, time to return to work, and complication rate were similar in the two groups. However, the operation time was significantly shorter in the FEID group than in the MD group, which indicated less tissue trauma leading to less infection rate. In 2017, Yorukoglu et al. have reported an infection rate of $0.14 \%$ in 835 patients who underwent endoscopic discectomy, which was lower than that of patients who had microscopic discectomy, as reported in the previous literature $(18,28)$.

During revisional microscopic discectomy, an extended muscle splitting dissection and laminectomy with further facetectomy can cause segmental instability and postoperative lowback pain. When the resection of spinal canal structures is prevented or the extent is reduced, the minimally traumatic disc resection may reduce the complications of the operation $(7,8,11,14,23,25)$. In relation to this reason, FEID is preferred in revision surgery for recurrent disc herniation. The goal of surgical treatment for recurrent disc herniation is sufficient decompression without neural injury and secondary postoperative trauma. Our study showed that adequate decompression with a low complication rate can be achieved with FEID for recurrent disc herniations.
Shin et al. have reported a recurrence rate of $4.8 \%$ after revisional disc surgery (25). The recurrence rate in our study was slightly higher than that in previous studies $(5.6 \%$ in the MD group and $5.2 \%$ in the FEID group). We believe that this result is attributed to the limited number of cases in our study.

Full endoscopic surgery is a sufficient alternative method to microsurgical procedures for revisional disc surgery. This is a minimally invasive surgical technique for discectomy, which has long been a validated and well-established standard procedure.

\section{CONCLUSION}

The findings of this study demonstrates that all recurrent lumbar disc herniations can be treated with minimally invasive procedures. Full endoscopic interlaminar approaches can be used and are an effective alternative to conventional revisional discectomy.

\section{Q REFERENCES}

1. Ahn Y, Lee SH, Park WM, Lee HY, Shin SW, Kang HY: Percutaneous endoscopic lumbar discectomy for recurrent disc herniation: Surgical technique, outcome, and prognostic factors of 43 consecutive cases. Spine 29:E326-332, 2004

2. Andersson GB, Brown MD, Dvorak J, Herzog RJ, Kambin P, Malter A, McCulloch JA, Saal JA, Spratt KF, Weinstein $\mathrm{JN}$ : Consensus summary on the diagnosis and treatment of lumbar disc herniation. Spine 21:75-78, 1996

3. Andrews DW, Lavyne $\mathrm{MH}$ : Retrospective analysis of microsurgical and standard lumbar discectomy. Spine 15:329335, 1990

4. Boyer P, Srour R, Buchheit F, Krause D, Albuquerque M: Lumbar disk hernia. Excision of hernia with or without complementary diskectomy? Neurochirurgie 40:259-262, 1994

5. Carragee EJ, Han MY, Suen PW, Kim D: Clinical outcomes after lumbar discectomy for sciatica: The effects of fragment type and anular competence. J Bone Jt Surg-Ser A 85:102108, 2003

6. Connolly ES: Surgery for recurrent lumbar disc herniation. Clin Neurosurg 39:211-216, 1992

7. Dasenbrock HH, Juraschek SP, Schultz LR, Witham TF, Sciubba DM, Wolinsky JP, Gokaslan ZL, Bydon A: The efficacy of minimally invasive discectomy compared with open discectomy: A meta-analysis of prospective randomized controlled trials. J Neurosurg Spine 16:452-462, 2012

8. Ebara S, Harada T, Hosono N, Inoue M, Tanaka M, Morimoto $\mathrm{Y}$, Ono K: Intraoperative measurement of lumbar spinal instability. Spine 17:S44-S50, 1992

9. Ebeling U, Kalbarcyk H, Reulen HJ: Microsurgical reoperation following lumbar disc surgery. Timing, surgical findings, and outcome in 92 patients. J Neurosurg 70:397-404, 1989

10. Ebeling U, Reichenberg W, Reulen HJ: Results of microsurgical lumbar discectomy-Review on 485 patients. Acta Neurochir (Wien) 81:45-52, 1986 
Goker B. and Aydin S: Surgery for Recurrent Disc Herniation

11. Eloqayli $\mathrm{H}, \mathrm{Al}-\mathrm{Omari} \mathrm{M}$ : Percutaneous discectomy: Minimally invasive method for treatment of recurrent lumbar disc herniation. Clin Neurol Neurosurg 114:871-875, 2012

12. Fairbank JC, Couper J, Davies JB, O’Brien JP: The Oswestry low back pain disability questionnaire. Physiotherapy 66:271273, 1980

13. Hubbe U, Franco-Jimenez P, Klingler JH, Vasilikos I, Scholz C, Kogias E: Minimally invasive tubular microdiscectomy for recurrent lumbar disc herniation. J Neurosurg Spine 24:48-53, 2015

14. Kotilainen $E$, Valtonen S: Clinical instability of the lumbar spine after microdiscectomy. Acta Neurochir (Wien)125:120-126, 1993

15. Law JD, Lehman RA, Kirsch WM: Reoperation after lumbar intervertebral disc surgery. J Neurosurg 48:259-263, 1978

16. Markovic M, Zivkovic N, Spaic M, Gavrilovic A, Stojanovic D, Aleksic V, Ruetten S: Full-endoscopic interlaminar operations in lumbar compressive lesions surgery: Prospective study of 350 patients. "Endos" study. J Neurosurg Sci 2016 (Epub ahead of print)

17. McCulloch JA: Focus issue on lumbar disc herniation: Macroand microdiscectomy. Spine 21:45-56, 1996

18. Roberts M: Complications of lumbar disc surgery. Spinal Surg 2:13-19, 1988

19. Ruetten S, Komp M, Godolias G: A new full-endoscopic technique for the interlaminar operation of lumbar disc herniations using 6-mm endoscopes: Prospective 2-year results of 331 patients. Minim Invasive Neurosurg 49:80-87, 2006

20. Ruetten S, Komp M, Godolias G: An extreme lateral access for the surgery of lumbar disc herniations inside the spinal canal using the full-endoscopic uniportal transforaminal approach-technique and prospective results of 463 patients. Spine 30:2570-2578, 2005
21. Ruetten S, Komp M, Merk H, Godolias G: Full-endoscopic interlaminar and transforaminal lumbar discectomy versus conventional microsurgical technique: A prospective, randomized, controlled study. Spine 33(9):931-939, 2008

22. Ruetten S, Komp M, Merk H, Godolias G: Use of newly developed instruments and endoscopes: Full-endoscopic resection of lumbar disc herniations via the interlaminar and lateral transforaminal approach. J Neurosurg Spine 6:521530, 2008

23. Schoeggl A, Maier $H$, Saringer W, Reddy M, Matula C: Outcome after chronic sciatica as the only reason for lumbar microdiscectomy. J Spinal Disord Tech 15:415-419, 2002

24. Sencer A, Yorukoglu AG, Akcakaya MO, Aras Y, Aydoseli A, Boyali O, Sencan F, Sabanci PA, Gomleksiz C, Imer M, Kırıs T, Hepgül K, Unal OF, Izgi N, Canbolat AT: Fully endoscopic interlaminar and transforaminal lumbar discectomy: Shortterm clinical results of 163 surgically treated patients. World Neurosurg 82:884-890, 2014

25. Shin KH, Chang HG, Rhee NK, Lim KS: Revisional percutaneous full endoscopic disc surgery for recurrent herniation of previous open lumbar discectomy. Asian Spine $\mathrm{J}$ 5:1-9, 2011

26. Stolke D, Sollmann WP, Seifert V: Intra- and postoperative complications in lumbar disc surgery. Spine 14:56-59, 1989

27. Swartz KR, Trost GR: Recurrent lumbar disc herniation. Neurosurg Focus 15:1-4, 2003

28. Yorukoglu AG, Goker B, Tahta A, Akcakaya MO, Aydoseli A, Sabanci PA, Aras Y, Alkir G, Sencer A, Imer M, Izgi N, Canbolat AT: Fully endoscopic interlaminar and transforaminal lumbar discectomy: Analysis of 47 complications encountered in a series of 835 patients. Neurocirugia 28:235-241, 2017 